\title{
Reply to Comment on: Wannamethee SG, Lowe GD0, Shaper AG, Rumley A, Lennon L, Whincup PH (2004) Insulin resistance, haemostatic and inflammatory markers and coronary heart disease risk factors in Type 2 diabetic men with and without coronary heart disease. Diabetologia 47:1557-1565
}

Received: 23 March 2005 / Accepted: 30 March 2005 / Published online: 26 May 2005

(C) Springer-Verlag 2005

To the Editor: We thank the authors for their letter regarding our paper, drawing attention to concerns about the validity of the homeostasis model assessment (HOMA) in elderly people with diabetes [1]. The two papers that the authors refer to suggest that the relation between HOMA and the insulin-glucose clamp gold standard may be weak or perhaps absent in patients with diabetes, although both these studies are based on small numbers of subjects $[2,3]$.

We agree that HOMA may not be the best measure of insulin resistance in elderly subjects with diabetes, an issue on which we have commented in our Discussion section. However, we do believe that in the present study, the HOMA model is likely to have had some validity as an indicator of insulin resistance in subjects with diabetes for two main reasons. Firstly, in the majority $(72 \%)$ of these subjects with diabetes, blood glucose concentration was below $9.5 \mathrm{mmol} / \mathrm{l}$, the level above which there has been particular concern about HOMA validity [4]. Secondly, among these subjects, HOMA was significantly correlated with BMI $(r=0.30 ; p<0.0001)$ as well as with markers of the insulin resistance syndrome, including waist circum-

S. G. Wannamethee $(\bowtie) \cdot$ A. G. Shaper

Department of Primary Care and Population Sciences,

Royal Free and University College Medical School,

Rowland Hill St,

London, NW3 2PF, UK

e-mail: goya@pcps.ucl.ac.uk

Tel.: +44-207-8302239

Fax: +44-207-7941224

P. H. Whincup

Department of Public Health Sciences,

St George's Medical School Hospital,

London, SW17 ORE, UK ference, triglycerides and HDL cholesterol $(r=0.30, r=0.43$ and $r=-0.34$ respectively; all $p<0.0001$ ). We would also point out that at present there is no alternative simple measure of insulin resistance suitable for use in populationbased studies.

We agree that more evidence is needed to confirm the validity of HOMA in elderly subjects with diabetes, or to provide an alternative measure of insulin resistance for use among such patients. In this cross-sectional study, we also observed that increasing HOMA is associated with increasing prevalence of CHD, suggesting that HOMA may also be a predictor of CHD in these older diabetic patients. Further prospective studies examining whether HOMA predicts the risk of incident CHD in older diabetic patients will help to resolve this issue.

\section{References}

1. Wannamethee SG, Lowe GDO, Shaper AG, Rumley A, Lennon L, Whincup PH (2004) Insulin resistance, haemostatic and inflammatory markers and coronary heart disease risk factors in type 2 diabetic men with and without coronary heart disease. Diabetologia 47:1557-1565

2. Ferrara C, Goldberg AP (2001) Limited value of the homeostasis model assessment to predict insulin resistance in older men with impaired glucose tolerance. Diabetes Care 24:245249

3. Katsuki A, Sumida Y, Urakawa H et al (2002) Neither homeostasis model assessment nor quantitative insulin sensitivity check index can predict insulin resistance in elderly patients with poorly controlled type 2 diabetes mellitus. J Clin Endocrinol Metab 87:5332-5335

4. Ono T, Shiga N, Taneda Y, Umemura S (1999) The fastingplasma glucose range in which insulin resistance measured by homeostasis model assessment correlates with euglycemic clamping. J Jpn Diabetes Soc 42:1005-1011 